\title{
Breast Cancer Management During the COVID-19 Pandemic: the Radiation Oncology Perspective
}

\author{
Christin A. Knowlton ${ }^{1}$
}

Accepted: 25 November 2021 / Published online: 26 February 2022

(c) The Author(s), under exclusive licence to Springer Science+Business Media, LLC, part of Springer Nature 2022

\begin{abstract}
Purpose of Review The coronavirus disease 19 (COVID-19) pandemic has caused disruption in healthcare throughout the world. The limitations placed on hospital resources and the need to limit potential exposure to SARS-CoV-2 for both patients and healthcare staff have affected oncologic care for patients with breast cancer (BC), including radiation therapy (RT). This review highlights published guidelines regarding the provision of radiotherapy for BC patients and their adoption by radiation oncology centers.

Recent Findings Multiple international and national consortiums plus select institutions have published formal recommendations regarding radiation therapy for BC during the COVID-19 pandemic. They embody the principles of limiting in-person visits, proper triage, and the judicious use of delay, abbreviation, or omission of RT as appropriate.

Summary Since the start of the pandemic, multiple publications have provided guidance regarding RT for BC during this challenging time. The pandemic has led to increased use of telemedicine and abbreviated radiation therapy courses in the setting of BC, which are likely to persist. Future research is needed to establish the effect of these changes on oncologic outcomes.
\end{abstract}

Keywords Breast cancer · Radiation therapy $\cdot$ Hypofractionation $\cdot$ COVID-19

\section{Introduction}

The ongoing pandemic of coronavirus disease 19 (COVID19), the disease caused by severe acute respiratory syndrome coronavirus 2 (SARS-CoV-2), continues to cause disruption in local and national economies, travel, healthcare, and day-to-day life across the globe. COVID-19 was initially declared a Public Health Emergency of International Concern in January 2020. Since that time, cases of COVID-19 have proliferated around the globe. One year later, there have been over 93 million cases of COVID-19 with over 2 million deaths worldwide, including over 23 million cases and 389,084 deaths in the USA [1].

This article is part of the Topical Collection on Breast Cancer Management during the COVID-19 Pandemic

Christin A. Knowlton

christin.knowlton@yale.edu

1 Department of Therapeutic Radiology, Yale School of Medicine, PO Box 208040, New Haven, CT, USA
The COVID-19 pandemic has impacted the delivery of standard treatment to patients with breast cancer (BC) in the USA and throughout the world, including radiation therapy (RT). During periods of high community spread, limited hospital resources and staffing are often allocated to meet the emergent needs of the high volume of COVID-19 patients, with the potential to lead to limitations on radiation oncology (RO) services. For example, the American Society for Radiation Oncology (ASTRO) conducted a national RO physician survey in April 2020 with results indicating that a large percentage of RO practices were experiencing a shortage of personal protective equipment $(69 \%)$, medical hand sanitizer (43\%), and nasopharyngeal swabs (26\%) [2]. A similar report by the European Society for Radiotherapy and Oncology (ESTRO) conducted in May 2020 reported that $57 \%$ of surveyed RO practices experienced a reduction in staff due to family care responsibilities related to COVID-19 (29\%), staff illness (26\%), and staff transfer to other clinical areas (13\%). Only $11 \%$ of practices reported that reduction in staff was due to decrease in patient volumes, indicating that these staff reductions may cause strain on the RO practices [3]. 
The need to limit potential exposure of patients as well as healthcare workers and staff during periods of high prevalence of COVID-19 supports decreasing the number of patients under treatment and the number of in-person visits. At this time, there are limited and conflicting data regarding increased risk of death or severe infection of COVID-19 for patients with cancer or recent anti-cancer treatment $[4$, $5,6]$. Nonetheless measures to decrease potential exposure of patients and healthcare providers and staff are crucial. A positive test and/or symptoms may have a range of consequences including disruption of anti-cancer treatment, hospitalization, and/or death.

Recommendations regarding adjustments in the provision of RT for BC patients during the COVID-19 pandemic have been published by international and national consortiums as well as select institutions. Published guidelines provide criteria to assist in performing proper triage to determine which patients can have their RT course delayed and/or abbreviated without significantly compromising oncologic outcomes. One of the most comprehensive and often cited recommendations regarding $\mathrm{BC}$ patient prioritization in the USA was published by the COVID-19 Pandemic Breast Cancer Consortium. Members represent the American Society of Breast Surgeons (ASBrS), the National Accreditation Program for Breast Centers (NAPBC), the National Comprehensive Cancer Network (NCCN), the Commission on Cancer (CoC), and American College of Radiology (ACR) [7••]. In Canada, Ontario Health has published the frequently referenced "Pandemic Planning Clinical Guideline for Patients with Cancer" $[8 \bullet \bullet$. There have been several published international endeavors including "International Guidelines on Radiation Therapy for Breast Cancer During the COVID-19 Pandemic" by Coles et al. with contributors from five continents [9•], RO guidelines published by the European Society for Medical Oncology (ESMO) [10•], and recommendations

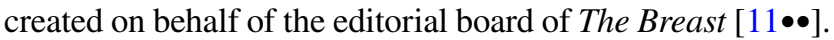
Several institutions including Johns Hopkins University, Memorial Sloan Kettering Cancer Center, and Yale School of Medicine have shared their respective approaches to RO treatment during the pandemic $[12,13,14]$.

This review explores the effects of the pandemic on radiation departmental operations as well as patient selection and treatment. Key published guidelines are highlighted to help RO practices provide responsible BC treatment that decreases the risk of exposure to COVID-19 while providing effective oncologic care.

\section{Basic Safety Guidelines/Telemedicine}

In order to limit the spread of SARS-CoV-2, multiple published guidelines recommend that all patients plus healthcare workers and staff wear masks. This has now become standard practice at almost all institutions $[3,15]$. Screening for symptoms of COVID-19 and recent travel to a high-risk area for patients with an in-person appointment either on the phone, at the door, or both is encouraged. Temperature screening for patients should be performed upon entry. Visitors and accompanying caregivers/family should not be allowed. Patients with symptoms or possible exposure to

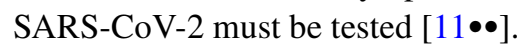

Multiple published guidelines recommend decreasing the number of patients to be seen in-person to limit the risk of spread of COVID-19 among patients and healthcare workers. The use of telemedicine is strongly encouraged in non-urgent situations and when physical examination is not paramount.

\section{Risk Stratification of Patients/Triage}

A common theme among the published guidelines related to $\mathrm{BC}$ care during the COVID-19 pandemic is risk stratification for proper triage of $\mathrm{BC}$ patients presenting for $\mathrm{RO}$ consultation and care. The Pandemic Planning Guideline for Patients with Cancer published by Ontario Health provides the basis for a 3-tiered system of Priority A (patients who are unstable, patients whose condition is intolerable without alternative available treatment or immediately life-threatening, rapidly progressing potentially curable tumors, patients already on treatment), Priority B (non-Priority A patients whose treatment can be deferred for a defined period of time without undue risk), and Priority $\mathrm{C}$ (patients that can be delayed until the pandemic is over) [8••]. The most detailed breakdown related to triage for $\mathrm{BC}$ radiation is provided by the COVID-19 Pandemic Breast Cancer Consortium, which following the concept of priority levels $\mathrm{A}, \mathrm{B}$, and $\mathrm{C}[\mathbf{7} \bullet \bullet$. This prioritization schema is detailed in Table 1 .

All guidelines stress the importance of approaching each patient's case on the individual level looking at the clinical situation, patient age and comorbidities, the current state of the pandemic on a local level, and the risk of mortality from COVID-19 as compared to the risk of delay of treatment. Several published guidelines stress the importance of continuing multidisciplinary tumor board in a web-based format to allow for discussion regarding proper triage and care of $\mathrm{BC}$ patients during the pandemic $[10 \bullet, 11 \bullet \bullet]$. In addition, the patient should be informed regarding the proposed treatment course as well as risks and benefits. The patient's preferences should be accounted for in treatment decision-making.

At our institution, our weekly breast multidisciplinary tumor board has been available via remote access for at least 7 years; however, prior to the COVID-19 pandemic, the vast majority of participants attended in-person. Starting in March 2020, the tumor board format was transitioned to $100 \%$ virtual. A survey regarding the experience was sent 
Table 1 Priority categories for radiation oncology for patients with $\mathrm{BC}$ during the COVID-19 pandemic per the COVID19 Pandemic Breast Cancer Consortium $[7 \bullet \bullet]$

\begin{tabular}{|c|c|}
\hline Priority level & Patient description \\
\hline A & $\begin{array}{l}\cdot \text { Bleeding/painful/symptomatic local, regional or metastatic disease } \\
\cdot \text { Progression of disease during neoadjuvant chemotherapy }\end{array}$ \\
\hline B1 & $\begin{array}{l}\cdot \text { Inflammatory BC after mastectomy } \\
\cdot \mathrm{LN}+\mathrm{TNBC} \text { or HER } 2+\text { disease following mastectomy } \\
\cdot 4 \text { or more positive lymph nodes } \\
\cdot \text { Residual and LN + disease following neoadjuvant chemotherapy }\end{array}$ \\
\hline B2 & $\begin{array}{l}\cdot 1-3 \text { positive lymph nodes following mastectomy } \\
\cdot \text { TNBC or HER } 2+, \text { LN- s/p BCS } \\
\cdot \text { Positive margin for invasive cancer s/p BCS with no alternative option (TNBC } \\
\text { takes priority) }\end{array}$ \\
\hline B3 & $\begin{array}{l}\cdot \text { Positive margin } \mathrm{s} / \mathrm{p} \text { BCS for invasive cancer with alternative therapy options } \\
\cdot \text {-Young age ( } \leq 40 \mathrm{yrs}) \mathrm{s} / \mathrm{p} \mathrm{BCS}, \mathrm{LN} \text { - with } \geq 1 \text { high feature (LVI +, PNI +) } \\
\cdot \text { ER- DCIS with positive margin }\end{array}$ \\
\hline $\mathrm{C}$ & $\begin{array}{l}\cdot \text { All other DCIS } \\
\cdot>65 \text { yrs, early stage, LN-, ER + /HER2- s/p BCS and taking endocrine therapy }\end{array}$ \\
\hline
\end{tabular}

$B C$ breast cancer, $L N$ lymph node, $T N B C$ triple negative breast cancer, HER2 human epidermal growth factor receptor 2, ER estrogen receptor, DCIS ductal carcinoma in situ out to all tumor board attendees in September 2020. Fiftyseven percent of respondents were "very satisfied", $38 \%$ were "somewhat satisfied", and 5\% were "somewhat dissatisfied" with attending the tumor board in virtual format. Fifty-seven percent of respondents stated that they were "very likely", and 19\% were "likely" to continue to attend tumor board virtually after the resumption of in-person meetings. Convenience was cited as a major factor. In addition, there has been an increase in attendance. For example, in September through November 2019, the mean number of weekly attendees at the breast multidisciplinary tumor board was 29.8 , and the median number was 28.5. In September through November 2020, the mean number of weekly attendees increased to 48.2, and the median number was 48 .

\section{Omission of Radiation Therapy}

All of the published guidelines reviewed recommend consideration of omission of RT for elderly BC patients in the post-operative setting who meet certain criteria, typically age $>65$ or 70 , tumor $\leq 2$ or $3 \mathrm{~cm}$ excised with negative margins, ER + , Her2- and lymph node negative and for whom endocrine therapy is planned.

For patients with invasive $\mathrm{BC}$, based on the results of CALGB 9343 at 12.6 years of median follow-up, omission of post-lumpectomy RT for BC patients with estrogen receptor positive tumors $<2 \mathrm{~cm}$ in size excised with negative margins (defined as no tumor on ink) and negative lymph nodes (clinically and/or pathologically) who take Tamoxifen has been shown to have no effect on breast cancer-specific survival, overall survival, and time to distant metastasis. There was a statistically significant increase in freedom from local-regional recurrence with RT (90 to 98\%); however, the lack of overall survival, breast cancer-specific survival, and distant metastasis-free survival with the inclusion of radiotherapy support its omission in this population [16].

At the time of publication of the reviewed guidelines, only the 5-year results of the PRIME II trial were available. This randomized trial included women aged $\geq 65$ years with hormone receptor-positive breast cancers up to $3 \mathrm{~cm}$ status-post-lumpectomy with negative margins $(\geq 1 \mathrm{~mm})$ and pathologically lymph node negative who were receiving endocrine therapy. Grade 3 tumor histology or lymphovascular invasion was permitted but not both. Patients were randomized to whole breast RT or observation. At median follow-up of 5 years, the rate of local recurrence was $1 \%$ in the RT arm and 4\% in the no-RT arm. There was no difference in overall survival, regional recurrence, and rate of distant metastasis. Only $3 \%$ of patients in the study had a grade 3 tumor which limits the applicability of these results to that group of patients [17].

Of note, the 10-year results of the PRIME II study were recently reported at the San Antonio Breast Cancer Symposium in December 2020. The rates of local recurrence in patients who did not receive RT were significantly increased compared to the RT arm (9.8\% vs $0.9 \%)$. There was also a significant increase in regional recurrence when radiotherapy was withheld ( $2.3 \%$ vs $0.5 \%)$. There was no significant difference found in breast cancer-specific survival, overall survival, and rate of distant metastasis. Most deaths were due to causes other than breast cancer. This provides additional support for withholding radiotherapy for patients $>65$ years of age who meet this criteria, especially during a time of scarce resources and the need to limit exposure to others [18].

Another group of patients for whom omission of RT can be considered is those with hormone receptor positive 
ductal carcinoma in situ (DCIS). Appropriate patients with DCIS who can forgo RT are those with mammographically detected lesions $<2.5 \mathrm{~cm}$, low or intermediate grade, and excised with negative margins $\geq 2 \mathrm{~mm}$ and over 40 years of age [13].

\section{Delay of Radiation Therapy}

For patients who do not fit the criteria for urgent RT, delay allows departments to minimize the number of patients being treated during periods of greater demand on hospital resources and high community spread. Delay of a determined amount of time, often 6-12 weeks, should be utilized for patients whose oncologic outcomes will not be adversely affected. Most patients fall into this group. This is a diverse group of patients who must be properly triaged to determine what constitutes an acceptable delay while balancing the risk of infection versus the risks of postponement of treatment. Each case must be considered on an individual basis.

It is logical that higher risk patients should have a shorter delay than patients with a lower risk BC. There are concerns regarding a potential increased risk of recurrence with delay of radiation therapy [19]. The risk stratification recommendations published by the COVID-19 Pandemic Breast Cancer Consortium as outlined in Table 1 provides a basis when determining what would constitute an acceptable delay that balances the risk of infection and oncologic outcome. For patients with hormone receptor positive BC, endocrine therapy should be started during the waiting period for RT. For most priority B patients, delay from 6 to 12 weeks is acceptable depending on risk factors. The acceptable time period for delay can range from as short as $<6-8$ weeks for higher risk patients (i.e., inflammatory BC post-mastectomy) up to 16-20 weeks for patients with early stage cancer s/p lumpectomy with negative margins (preferably $\geq 2 \mathrm{~mm}$ ), lymph node negative, hormone receptor positive patients who take endocrine therapy, and $>50$ years of age [20, $21,22]$. Nonetheless, regardless of priority and risk factors, delay should be minimized taking into account available hospital resources and local prevalence of COVID-19.

\section{Abbreviated Radiation Treatment Courses}

During the pandemic, when resources are tight and the risk of exposure to SAR-CoV-2 is elevated, the use of abbreviated RT courses is encouraged. Available techniques are moderate hypofractionation, ultra-hypofractionation, omission of boost, simultaneous integrated boost (SIB), and accelerated partial breast irradiation (APBI).

The use of moderate hypofractionation for whole breast RT following lumpectomy without inclusion of regional lymph nodes has been well-studied and was already considered standard of care in many countries including the

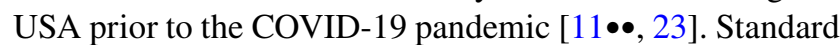
moderate hypofractionation courses for whole breast RT are $40 \mathrm{~Gy}$ in 15 fractions [24] and $42.5 \mathrm{~Gy}$ in 16 fractions [25]. If boost is utilized, $10 \mathrm{~Gy}$ in 4 fractions is prescribed in lieu of the traditional 5 or 8 fraction boost. An additional fraction of $2.5 \mathrm{~Gy}$ can be considered in the setting of high-risk factors such as young age and/or a close or positive margin [23].

At the onset of the pandemic, moderate hypofractionation regimens had not been widely adopted in the USA in the setting of PMRT. The data regarding use of moderate hypofractionation in the setting of regional nodal RT and postmastectomy RT is less robust [26-28]. There is a growing body of maturing and accruing prospective and randomized trials examining use of moderate hypofractionation in PMRT with and without reconstruction which suggests that there is confidence in equivalence in clinical outcomes, as shown in Table 2. Based on available data, early adoption of these regimens is reasonable during a crisis of limited resources and risk of exposure to SARS-CoV-2. Caution is advised for patients $<45$ years of age, triple negative cancers, extensive nodal involvement, and residual disease after pre-operative chemotherapy [12]. Based on physician judgment, these patients may be better served by conventional fractionation.
Table 2 Moderate

hypofractionation and ultrahypofractionation RT regimens for the treatment of $\mathrm{BC}$

\begin{tabular}{lll}
\hline RT type & Fractionation schemes & Relevant publications/trials \\
\hline Whole breast & $\cdot 2.67 \mathrm{~Gy} \times 15$, daily & UK START B [24] \\
& $\cdot 2.66 \mathrm{~Gy} \times 16$, daily & Whelan et al. Canadian [25] \\
& $\cdot 5.7 \mathrm{~Gy} \times 5$, once weekly & FAST [29] \\
& $\cdot 5.2 \mathrm{~Gy} \times 5$, daily & FAST-Forward [30] \\
Partial breast & $\cdot 6 \mathrm{~Gy} \times 5$, every other day (IMRT) & APBI-IMRT-Florence Trial [31] \\
Post-mastectomy & $\cdot 2.9 \mathrm{~Gy} \times 15 \mathrm{CW} ; 2.5 \mathrm{~Gy} \times 14 \mathrm{RN}$, daily & Wang et al. Chinese phase III [28] \\
& $\cdot 2.66 \mathrm{~Gy} \times 16$, daily & NCT03414970 \\
& $\cdot 2.67 \mathrm{~Gy} \times 15 \mathrm{CW} ; 2.67 \mathrm{~Gy} \times 14 \mathrm{RN}$, daily & NCT03422003 (FABREC) \\
Boost & $\cdot 2.5 \mathrm{~Gy} \times 4$, daily & ASTRO guidelines [23] \\
\hline
\end{tabular}

$R T$ radiation therapy, $B C$ breast cancer, $I M R T$ intensity-modulated radiation therapy, $R N$ regional nodes 
Ultra-hypofractionation including the FAST regimen (28.5 Gy in 5 fractions delivered once-weekly) and the FAST Forward (26 Gy in 5 fractions over 1 week) may also be used for patients with early stage BC (T1-2, N0) statuspost-lumpectomy who do not require nodal treatment or a boost. Evidence to support these regimens has strengthened since the initial publication of the reference guidelines. Tenyear results from FAST, a phase III trial showing equivalent outcomes in regard to local recurrence and normal tissue effects for the FAST regimen $(28.5 \mathrm{~Gy}$ in 5 fractions once weekly), were recently published [29]. Our institution has offered FAST to appropriate candidates since publication of the full manuscript detailing the 10-year results. The 5 -year results of the phase III FAST Forward trial were also recently published showing non-inferiority of $26 \mathrm{~Gy}$ in 5 fractions delivered over 1 week compared to $40 \mathrm{~Gy}$ in 15 fractions in regard to local control and normal tissue effects [30]. Due to the shorter term follow-up, this regimen should be adopted with caution; however, during the unique conditions of a global pandemic, the use of this regimen for appropriate patients who are aware of the risks and benefits is reasonable. Table 2 outlines published hypofractionation regimens to be considered for use and supporting data.

Published guidelines recommend judicious omission of tumor boost during the pandemic. Boost should be reserved for patients of higher risk of local relapse. Examples of high-risk factors include age $\leq 40-50$, residual disease after neoadjuvant chemotherapy, high-grade tumor, and positive margin. SIB can be considered; however, phase III data regarding its use are not yet available [32].

The thoughtful application of APBI for appropriate cases is also advocated in several published reports. Brachytherapy is discouraged because it adds additional strain on hospital resources and entails longer and more involved hospital visits $[10 \bullet, 13]$. Conventional external beam APBI is delivered in $38.5 \mathrm{~Gy}$ in 10 fractions BID. To further limit visits to the department, 30 Gy delivered in 5 fractions delivered every other day using intensity-modulated radiation therapy (IMRT) is an option for departments with the necessary expertise [31]. APBI should be limited to patients who fit ASTRO's suitable classification. APBI may be considered for patients in the cautionary group especially during more active periods of the pandemic [33].

\section{Interruptions in Radiation Treatment}

Interruption of anti-cancer treatment including radiation therapy is recommended for patients who test positive for COVID-19 until they are medically cleared and transmission-based precautions can be discontinued [34]. This is for the protection of both the patient and staff. The Center for Disease Control provides detailed guidelines providing when discontinuation of transmission-based precautions can occur. The use a symptom-based strategy is preferred, with isolation periods of minimum of 10 to 20 days since onset of symptoms based on initial severity of disease and immunocompromised state of the patient, at least $24 \mathrm{~h}$ since last fever without use of fever-reduction medication, and improvement of symptoms [35]. Of note, a recent meta-analysis indicates that RT is not associated with an increased risk of severe disease or death from COVID-19 [36]; however, caution is advised as data remain limited. In limited cases for patients considered Priority A when interruption in treatment may be life threatening or have a significant deleterious effect on oncologic outcome, continuing to treat can be considered on a case-by-case basis. These patients should be treated at the end of the day after all patients and non-essential staff have left. Treating staff must wear full personal protective equipment.

In September 2017, Puerto Rico was devastated by Hurricane Maria which caused catastrophic damage leaving $100 \%$ of the island without power in its aftermath. This led to interruption in RT for essentially every patient undergoing radiation on the island. ASTRO assembled a panel of experts in various cancer types, including breast, to provide recommendations regarding how to manage unexpected interruptions in radiotherapy [37•]. These recommendations were published in Practical Radiation Oncology and formed the basis for guidance regarding the use of altered fractionation to compensate for a 2-3-week interruption in treatment. Similar compensatory fractionation schemes were included in the guidelines disseminated by the COVID-19 Pandemic Breast Cancer Consortium, Johns Hopkins, and Yale $[7 \bullet \bullet, 12,14]$. The recommendations are summarized in Table 3. At our institution, at this time since the onset of the pandemic in March 2020, there have been 12 patients who experienced delay, only one of whom had a diagnosis of breast cancer.

\section{Adoption of Recommendations}

There are multiple published reports indicating that RO departments adopted the recommended strategies of telemedicine as well as delay, omission, and/or abbreviation of RT designed to limit the number of departmental visits and treatments thereby decreasing potential SARS-CoV-2 exposure of patients and staff and placing less pressure on hospital resources.

ASTRO surveyed RO practices in the USA from April 16 to April 30, 2020. Practices reported that their treatment volume was at $68 \%$ of typical on average. Ninety-two percent reported strategically delaying lower risk patients. Ninety-nine percent required staff to wear masks, and $98 \%$ 
Table 3 Recommendations for dose compensation for patients with BC following a 2-3-week delay in RT. Adapted from Gay et al. $[37 \bullet]$

\begin{tabular}{|c|c|}
\hline RT type & Recommendations \\
\hline Whole breast only & $\begin{array}{l}\text { - Continue with originally planned fractionation } \\
\text {-Adjust boost as follows: } \\
\text {-If initial plan did not include boost: add } 2 \mathrm{~Gy} \times 5 \text { fraction boost } \\
\text {-If sequential boost planned: add one } 2 \mathrm{~Gy} \text { fraction per week } \\
\text { missed up to } 66 \mathrm{~Gy} \text { to lumpectomy cavity PTV or change boost to } \\
2.3 \mathrm{~Gy} \times 5 \\
\text {-If original boost was to } 66 \mathrm{~Gy} \text {, increase up to } 70 \mathrm{~Gy} \text { (considering } \\
\text { reducing the volume size to highest risk area) }\end{array}$ \\
\hline Chest wall $(\mathrm{CW})$ & -Same as above but boost volume is mastectomy scar PTV \\
\hline RNI with whole breast or CW & -Adjust dose to a maximum of $50 \mathrm{~Gy}$ in $2 \mathrm{~Gy}$ fractions \\
\hline
\end{tabular}

$B C$ breast cancer, $R T$ radiation therapy, $P T V$ planning target volume, $R N I$ regional nodal irradiation were screening patients prior to entry. Ninety percent of practices reported limiting visitors. Eighty-nine percent were offering telemedicine for patient consultations $[2$, 15].

Belkacemi et al. reported upon their single institutional experience in Paris during the initial wave of the COVID-19 pandemic. Telemedicine was vigorously instituted including for weekly on treatment visits. After March 13, 2020, 50 patients who had undergone $\mathrm{CT}$ simulation including 6 who were already on treatment were identified at chart rounds as eligible for delay or shortening of their treatment course. Sixty-four percent of the identified cases were BC patients. Among the 50 cases identified, 22 had delay of treatment. Thirty-nine percent of those with delay in treatment were BC patients of whom the majority received endocrine therapy during the waiting period. Twenty one out of the 50 patients were BC patients who received a hypofractionated course. From March 15 to May 31, 2020, the expected number of fractions delivered would have been 1383; however, with delay of treatment and the use of hypofractionation for appropriate $\mathrm{BC}$ and other patients, the number of actual fractions delivered was decreased to 683 , a $50 \%$ reduction [38].

A national survey of RO practice patterns in Switzerland during the COVID-19 pandemic was conducted by Achard et al. in April 2020. Telemedicine was rapidly instituted at all centers. Results were mixed regarding implementation of the recommended strategies to omit, delay, and abbreviate radiation courses. For example, 50\% of centers reported omitting RT boost in lower risk patients. Only $9 \%$ of centers omitted RT in patients $\geq 65$ years of age with $\mathrm{ER}+$ invasive tumor measuring $<3 \mathrm{~cm}$ with clear margins, grades $1-2$, and lymph node negative who planned to take endocrine therapy. Fifty percent of RO centers reported the use of endocrine therapy to delay start of RT in ER + early stage BC or DCIS. It is notable that there was an $18 \%$ increase in the percentage of centers providing moderate hypofractionation (i.e., 15 or 16 fraction regimen) compared to prior to the pandemic, with an increase from 64 to $82 \%$. Only 1 center, representing
$5 \%$ of respondents, reported using ultra-hypofractionation with the FAST or FAST Forward regimen [39].

A similar survey was conducted by the European Breast Cancer Research Association of Surgical Trialists (EURBREAST) in April 2020 with responses mostly from public or university-affiliated hospitals treating over 300 cases per year from 41 countries with most being located in Europe. $51.9 \%$ of responding institutions reported that they made no changes in RT offered for BC patients. RT was postponed for low-risk patients at $22.6 \%$ of represented facilities. $15.9 \%$ of respondents reported implementing moderate hypofractionation, and $7.4 \%$ reported implementing ultra-hypofractionated regimens [40].

Other departments report more aggressive adoption of ultra-hypofractionation. For example, in a letter published in December 2020, Guy's Cancer Centre in London reported that they began to offer the Fast Forward regimen to suitable patients due to the pandemic starting in March 2020. From March 1 through May 7, 2020, there were 121 patients with early stage BC deemed suitable for ultra-hypofractionated treatment, which is a decrease in patient volume by $19 \%$ from the year prior reflecting the omission of RT. During this time period, 53\% of patients received the FAST Forward regimen, $46 \%$ received moderate hypofractionation (40 Gy in 15 fractions), and only 1 patient received 50 Gy in 25 fractions. Note that all cases of in situ cancer received moderate fractionation [41].

A group of 20 expert panelists reviewed 54 publications including 233 recommended adaptations in dose fractionation during the COVID-19 pandemic and compared the quality of evidence supporting established dose fractionation schemes commonly employed in the pre-COVID era as compared to the shortened courses recommended for the in-COVID era. The panel found that for curative-intent fractionation schedules, pre-COVID fractionation courses were more likely to be supported by high-quality evidence (51.4\%) as opposed to expert opinion (4.8\%). Recommended in-COVID hypofractionation schedules demonstrated the reverse, with $5.6 \%$ supported by high-quality evidence and 
$49.3 \%$ deemed to be expert opinion. In the realm of BC, however, it was noted that the use of moderate hypofractionation was already supported by high-quality evidence and the use of ultra-hypofractionation ( 5 fractions) was supported by moderate quality evidence such that the difference in the levels of evidence between the highest-quality schedules to the recommended in-COVID fractionation schedules is described as "minimal" [42]. For this reason, it is likely that many radiation oncologists felt comfortable embracing the shortened courses recommended by the various published guidelines.

\section{Conclusion}

The COVID-19 pandemic has constrained availability of supplies and healthcare personnel during periods of high community spread, which has affected RO practices around the world [2,3]. In addition, the need to limit in-person interactions has led to standard safety practices including temperature and travel screening of patients/visitors, the placement of limitations on visitors, wearing of masks by all staff and patients, and the rapid growth of telemedicine [2, 3, 15]. Multiple international, national, and institutional groups have published recommendations regarding proper triage of RO patients with $\mathrm{BC}$ that provide guidance regarding prioritization of patients during times of limited resources and staff when patients may need to be delayed $[7 \bullet \bullet, 8 \bullet \bullet, 9 \bullet, 10 \bullet$, $11 \bullet \bullet, 12-14]$. Selective delay of appropriate patients with $\mathrm{BC}$ also allows for decreased person-to-person interactions until SARS-CoV-2 transmission rates are lower. Judicious omission of radiation therapy is also an important strategy to curtail the number of patient visits and treatments while maintaining optimum oncologic outcomes.

Published guidelines encourage the use of moderate hypofractionation and ultra-hypofractionation for appropriate patients with $\mathrm{BC}$. While moderate hypofractionation was already widely adopted for patients requiring treatment to the breast without inclusion of the regional lymph nodes $[11 \bullet \bullet, 23]$, the pandemic coupled with recent updated publications on the FAST and FAST Forward trials have accelerated the use of ultra-hypofractionation for patients with early stage BC [29, 30, 41].

Vaccines to protect patients from development of COVID-19 have recently become available. Due to limited supply chains and the difficulties associated with vaccinating the world population, it will be months and possibly years until an adequate number of the world's population has been vaccinated to reach herd immunity. There has also been the recent global spread of more infectious variants of SARS-CoV-2. For these reasons, the timeline for the end of the COVID-19 pandemic remains uncertain. It is quite likely that some of the changes in $\mathrm{RO}$ for patients with BC, including telemedicine, virtual multidisciplinary tumor board, and the increased use of moderately and ultrafractionated treatment courses, will remain after the global COVID-19 pandemic has eased. Future research will help define the long-term oncologic effects of the strategies of triage/prioritization, select omission or delay of RT, and the abbreviation of RT treatment courses.

\section{Declarations}

Conflict of Interest The author declares no competing interests.

Human and Animal Rights and Informed Consent This article does not contain any studies with humans or animal subjects performed by any of the authors.

\section{References}

Papers of particular interest, published recently, have been highlighted as:

- Of importance

$\bullet$ Of major importance

1. World Health Organization: WHO weekly epidemiological update - 19 January 2021. https://www.who.int/publicatio ns/m/item/weekly-epidemiological-update---19-january-2021. Accessed 23 Jan 2021.

2. ASTRO: COVID-19's impact on radiation oncology. 2020. https://www.astro.org/ASTRO/media/ASTRO/News\%20and\% 20Publications/PDFs/ASTROCOVID19Survey1-ExecSummary. pdf. Accessed 31 Jan 2021.

3. Slotman BJ, Lievens Y, Poortmans P, Cremades V, Eichler T, Wakefield DV, Ricardi U. Effect of COVID-19 pandemic on practice on European radiation oncology centers. Radiother Oncol. 2020;150:40-2. https://doi.org/10.1016/j.radonc.2020. 06.007 .

4. Liang W, Guan W, Chen R, Wang W, Li J, Xu K, et al. Cancer patients in SARS-CoV-2 infection: a nationwide analysis in China. Lancet Oncol. 2020;21:335-7. https://doi.org/10.1016/ S1470-2045(20)30096-6.

5. Lee LY, Cazier J, Angelis V, Arnold R, Bisht V, Campton NA, et al. COVID-19 mortality in patients with cancer on chemotherapy or other anticancer treatments: a prospective cohort study. Lancet. 2020;395:1919-26. https://doi.org/10.1016/S01406736(20)31173-9.

6. Kuderer NM, Choueiri TK, Shah DP, Shyr Y, Rubenstein SM, Rivera DR, et al. Clinical impact of COVID-19 on patients with cancer (CCC19): a cohort study. Lancet. 2020;395:1907-18. https://doi.org/10.1016/S0140-6736(20)31187-9.

7.• Dietz JR, Moran MS, Isakoff SI, Kurtzman SH, Willey SC, Burstein HJ, et al. Recommendations for prioritization, treatment and triage of breast cancer patients during the COVID-19 pandemic the COVID-19 pandemic breast cancer consortium. Breast Cancer Res Treat. 2020;181:487-97. https://doi.org/10. 1007/s10549-020-05644-z (These comprehensive guidelines provide detailed guidance regarding triage of patients with BC. Members of the COVID-19 Pandemic Breast Cancer 
Consortium represent the American Society of Breast Surgeons (ASBrS), the National Accreditation Program for Breast Centers (NAPBC), the National Comprehensive Cancer Network (NCCN), the Commission on Cancer (CoC), and American College of Radiology (ACR).).

8.• Ontario Health. Pandemic planning clinical guideline for patients with cancer. 2020. https://www.accc-cancer.org/docs/documents/ cancer-program-fundamentals/oh-cco-pandemic-planning-clini cal-guideline_final_2020-03-10.pdf. Accessed 31 Jan 2021. This guideline, published early in the pandemic, delineates the concept of prioritization of patients with cancer during the pandemic upon which multiple other published guidelines are based.

9. $\bullet$ Coles CE, Aristei C, Bliss J, Boersma L, Brunt AM, Chatterjee $\mathrm{S}$, et al. International guidelines on radiation therapy for breast cancer during the COVID-19 pandemic. Clin Oncol (R Coll Radiol). 2020;32:279-81. https://doi.org/10.1016/j.clon.2020. 03.006 (This set of guidelines specific to RT for patients with $\mathrm{BC}$ with authors from five continents is frequently cited in publications related to the treatment of $\mathrm{BC}$ patients during the pandemic.).

10. •de Azambuja E, Trapani D, Loibl S, Delaloge S, Senkus E, Criscitiello C, et al. ESMO Management and treatment adapted recommendations in the COVID-19 era: breast Cancer. ESMO Open. 2020;5(Suppl 3): e000793. https://doi.org/10.1136/esmoo pen-2020-000793 (This important publication from ESMO provides guidance for treatment of $\mathrm{BC}$ patients during the pandemic with attention to the radiological and pathological diagnosis of $\mathrm{BC}$, breast surgical oncology, radiation oncology, and medical oncology.)

11. •Curigliano G, Cardoso MJ, Poortmans P, Gentilini O, Pravettoni G, Mazzocco K, et al. editorial board of The Breast Recommendations for triage, prioritization and treatment of breast cancer patients during the COVID-19 pandemic. Breast. 2020;52:8-16. https://doi.org/10.1016/j.breast.2020.04.006 (This comprehensive publication addresses the care of $\mathrm{BC}$ patients by all modalities with recommendations tailored to the local severity of the pandemic.).

12. Johns Hopkins University Dept of Radiation Oncology \& Molecular Radiation Sciences. An integrated program in a pandemic: Johns Hopkins Hospital, Bayview Hospital, Green Spring Station, Sibley Memorial Hospital, Suburban Rockledge Site. 2020. https://www.astro.org/ASTRO/media/ASTRO/Daily\%20Pra ctice/PDFs/JHUPrograminaPandemic040320.pdf. Accessed 31 Jan 2021.

13. Braunstein LZ, Gillespie EF, Hong L, Xu A, Bakhoum SF, Cuaron J, et al. Breast radiation therapy under COVID-19 pandemic resource constraints-approaches to defer or shorten treatment from a comprehensive cancer center in the United States. Adv Radiat Oncol. 2020;5:582-8. https://doi.org/10.1016/j.adro. 2020.03.013.

14. Yu, JB. COVID Yale radiation oncology flowchart. ROhub. 2020. https://rohub.astro.org/communities/community-home/ digestviewer/viewthread?MessageKey=9ac16312-3905-4303bd5b-22549c0be6e6\&CommunityKey $=881 \mathrm{f} 9 \mathrm{cc} 8-10 \mathrm{ec}-45 \mathrm{~b} 6-$ ad5f-5ff678d86fdd\&tab=digestviewer\#bm61dc0ea1-9fd7-4b65a73c-65e6568fbbf9. Accessed 31 Jan 2021.

15. Wakefield DV, Sanders T, Wilson E, Hubler A, DeWeese T, Smith BD, et al. Initial impact and operational responses to the COVID-19 pandemic by American Radiation Oncology Practices. Int J Radiat Oncol Biol Phys. 2020;108:356-61. https:// doi.org/10.1016/j.ijrobp.2020.06.060.

16. Hughes KS, Schnaper LA, Bellon JR, Cirrincione CT, Berry DA, McCormick B, et al. Lumpectomy plus tamoxifen with or without irradiation in women age 70 years or older with early breast cancer: long-term follow-up of CALGB 9343. J Clin Oncol. 2013;31:2382-7. https://doi.org/10.1200/JCO.2012.45.2615.

17. Kunkler IH, Williams LJ, Jack WJ, Cameron DA, Dixon JM, PRIME II investigators. Breast-conserving surgery with or without irradiation in women aged 65 years or older with early breast cancer (PRIME II): a randomised controlled trial. Lancet Oncol. 2015;16:266-73. https://doi.org/10.1016/S14702045(14)71221-5.

18. Kunkler IH, Williams LJ, Jack WJ, Cameron DA, Dixon JM. Prime 2 randomised trial (postoperative radiotherapy in minimum-risk elderly): Wide local excision and adjuvant hormonal therapy $+/$ - whole breast irradiation in women $=/>65$ years with early invasive breast cancer: 10 year results [abstract]. In San Antonio Breast Cancer Symposium; 2020 Dec 8-11. Abstract GS2-03. https://www.sabcs.org/Portals/SABCS2016/ $2020 \% 20$ SABCS/ALL\%20ABSTRACTS\%202-9.pdf?ver= 2020-12-09-104626-337. Accessed 31 Jan 2021.

19. Huang J, Barbera L, Brouwers M, Browman G, Mackillop WJ. Does delay in starting treatment affect the outcomes of radiotherapy? A systematic review J Clin Oncol. 2003;21:555-63. https://doi.org/10.1200/JCO.2003.04.171.

20. Olivotto IA, Lesperance ML, Truong PT, Nichol A, Berrang $\mathrm{T}$, Tyldesley $\mathrm{S}$, et al. Intervals longer than 20 weeks from breast-conserving surgery to radiation therapy are associated with inferior outcome for women with early-stage breast cancer who are not receiving chemotherapy. J Clin Oncol. 2009;27:16-23. https://doi.org/10.1200/JCO.2008.18.1891.

21. Karlsson P, Cole BF, Colleoni M, Roncadin M, Chua BH, Murray E, International Breast Cancer Study Group, et al. Timing of radiotherapy and outcome in patients receiving adjuvant endocrine therapy. Int J Radiat Oncol Biol Phys. 2011;80:398-402. https://doi.org/10.1016/j.ijrobp.2010.02. 042.

22. Vujovic O, Yu E, Cherian A, Dar AR, Stitt L, Perera F. Time interval from breast-conserving surgery to breast irradiation in early stage node-negative breast cancer: 17-year follow-up results and patterns of recurrence. Int J Radiat Oncol Biol Phys. 2015;91:319-24. https://doi.org/10.1016/j.ijrobp.2014.10.006.

23. Smith BD, Bellon JR, Blitzblau R, Freedman G, Haffty B, Hahn $\mathrm{C}$, et al. Radiation therapy for the whole breast: executive summary of an american society for radiation oncology (ASTRO) evidence-based guideline. Pract Radiat Oncol. 2018;8:145-52. https://doi.org/10.1016/j.prro.2018.01.012.

24. Haviland JS, Owen JR, Dewar JA, Agrawal RK, Barrett J, Barrett-Lee PJ, START Trialists' Group, et al. The UK standardisation of breast radiotherapy (START) trials of radiotherapy hypofractionation for treatment of early breast cancer: 10-year follow-up results of two randomised controlled trials. Lancet Oncol. 2013;14:1086-94. https://doi.org/10.1016/S14702045(13)70386-3.

25. Whelan TJ, Pignol JP, Levine MN, Julian JA, MacKenzie R, Parpia S, et al. Long-term results of hypofractionated radiation therapy for breast cancer. N Engl J Med. 2010;362(6):513-20. https://doi.org/10.1056/NEJMoa0906260.

26. Leong N, Truong PT, Tankel K, Kwan W, Weir L, Olivotto IA. Hypofractionated nodal radiation therapy for breast cancer was not associated with increased patient-reported arm or brachial plexopathy symptoms. Int J Radiat Oncol Biol Phys. 2017;99:1166-72. https://doi.org/10.1016/j.jirobp.2017.07.043.

27. Chitapanarux I, Klunklin P, Pinitpatcharalert A, Sripan P, Tharavichitkul E, Nobnop W, et al. Conventional versus hypofractionated postmastectomy radiotherapy: a report on long-term outcomes and late toxicity. Radiat Oncol. 2019;14:175. https:// doi.org/10.1186/s13014-019-1378-x.

28. Wang SL, Fang H, Song YW, Wang WH, Hu C, Liu YP, et al. Hypofractionated versus conventional fractionated 
postmastectomy radiotherapy for patients with high-risk breast cancer: a randomised, non-inferiority, open-label, phase 3 trial. Lancet Oncol. 2019;20:352-60. https://doi.org/10.1016/S14702045(18)30813-1.

29. Brunt AM, Haviland JS, Sydenham M, Agrawal RK, Algurafi $\mathrm{H}$, Alhasso A, et al. Ten-year results of FAST: a randomized controlled trial of 5-fraction whole-breast radiotherapy for early breast cancer. J Clin Oncol. 2020;38:3261-72. https://doi.org/10. 1200/JCO.19.02750.

30. Brunt AM, Haviland JS, Wheatley DA, Sydenham MA, Alhasso A, Bloomfield DJ, FAST-Forward Trial Management Group, et al. Hypofractionated breast radiotherapy for 1 week versus 3 weeks (FAST-Forward): 5-year efficacy and late normal tissue effects results from a multicentre, non-inferiority, randomised, phase 3 trial. Lancet. 2020;395:1613-26. https://doi.org/10. 1016/S0140-6736(20)30932-6.

31. Meattini I, Marrazzo L, Saieva C, Desideri I, Scotti V, Simontacchi G, et al. Accelerated partial-breast irradiation compared with whole-breast irradiation for early breast cancer: long-term results of the randomized phase III APBI-IMRT-Florence Trial. J Clin Oncol. 2020;38:4175-83. https://doi.org/10.1200/JCO.20. 00650.

32. Freedman GM, White JR, Arthur DW, Allen Li X, Vicini FA. Accelerated fractionation with a concurrent boost for early stage breast cancer. Radiother Oncol. 2013;106:15-20. https://doi.org/ 10.1016/j.radonc.2012.12.001.

33. Correa C, Harris EE, Leonardi MC, Smith BD, Taghian AG, Thompson AM, et al. Accelerated partial breast irradiation: executive summary for the update of an ASTRO evidence-based consensus statement. Pract Radiat Oncol. 2017;7:73-9. https:// doi.org/10.1016/j.prro.2016.09.007.

34. Al-Shamsi HO, Alhazzani W, Alhuraiji A, Coomes EA, Chemaly $\mathrm{RF}$, Almuhanna M, et al. A practical approach to the management of cancer patients during the novel coronavirus disease 2019 (COVID-19) pandemic: an international collaborative group. Oncologist. 2020;25:e936-45. https://doi.org/10.1634/ theoncologist.2020-0213.

35. Center for Disease Control. Discontinuation of transmissionbased precautions and disposition of patients with COVID-19 in healthcare settings (interim guidance). 2020. https://www.cdc. gov/coronavirus/2019-ncov/hcp/disposition-hospitalized-patie nts.html. Accessed 1 Feb 2021.

36. Yekedüz E, Utkan G, Ürün Y. A systematic review and metaanalysis: the effect of active cancer treatment on severity of COVID-19. Eur J Cancer. 2020;141:92-104. https://doi.org/10. 1016/j.ejca.2020.09.028.
37. •Gay HA, Santiago R, Gil B, Remedios C, Montes PJ, LopezAraujo J, et al. Lessons learned from Hurricane Maria in Puerto Rico: practical measures to mitigate the impact of a catastrophic natural disaster on radiation oncology patients. Pract Radiat Oncol. 2019;9:305-21. https://doi.org/10.1016/j.prro.2019. 03.007 (The challenging situation in Puerto Rico following the mass destruction by Hurricane Maria led to significant unexpected treatment interruptions for RO patients. This publication provides guidance on how to best manage RO patients during a disaster.).

38. Belkacemi Y, Loaganadane G, Grellier N, Fonteneau G, Zaoui G, Coraggio G, et al. Radiation therapy department reorganization during the coronavirus disease 2019 (COVID-19) outbreak: keys to securing staff and patients during the first weeks of the crisis and impact on radiation therapy practice from a single institution experience. Adv Radiat Oncol. 2020;5:644-50. https://doi.org/10.1016/j.adro.2020.04.039.

39. Achard V, Aebersold DM, Allal AS, Andratschke N, Baumert $\mathrm{BG}$, Beer KT, et al. A national survey on radiation oncology patterns of practice in Switzerland during the COVID-19 pandemic: present changes and future perspectives. Radiother Oncol. 2020;150:1-3. https://doi.org/10.1016/j.radonc.2020.05.047.

40. Gasparri ML, Gentilini OD, Lueftner D, Kuehn T, Kaidar-Person $\mathrm{O}$, Poortmans P. Changes in breast cancer management during the corona virus disease 19 pandemic: an international survey of the European Breast Cancer Research Association of Surgical Trialists (EUBREAST). Breast. 2020;52:110-5. https://doi.org/ 10.1016/j.breast.2020.05.006.

41. Hanumanthappa N, Goldsmith C, Sawyer E, Tutt A, Castell F, Azad G, et al. Adjuvant breast radiotherapy at an academic centre during the COVID-19 pandemic: reassuringly safe. Clin Oncol (R Coll Radiol). 2020. https://doi.org/10.1016/j.clon. 2020.12.013.

42. Thomson DJ, Yom SS, Saeed H, El Naqa I, Ballas L, Bentzen SM, et al. Radiation fractionation schedules published during the COVID-19 pandemic: a systematic review of the quality of evidence and recommendations for future development. Int $\mathbf{J}$ Radiat Oncol Biol Phys. 2020;108:379-89. https://doi.org/10. 1016/j.jirobp.2020.06.054.

Publisher's Note Springer Nature remains neutral with regard to jurisdictional claims in published maps and institutional affiliations. 